\title{
OCHO APORTACIONES CLÍNICAS DE FREUD SOBRE LA VOZ
}

\author{
Oito Contribuições Clínicas Freud na Voz
}

Eight Clinical Freud's Contributions of Voice

Artigo Original

Huit Apports Cliniques de Freud sur la Voix

\begin{abstract}
Resumen
El objetivo de este texto es mostrar los avances de una investigación sobre la voz. En este caso se trata de exponer algunos de los aportes y observaciones clínicos de Freud. En la medida que no hizo de la voz un concepto Freud oscila entre la noción de voz como fenómeno y la noción de voz como resto irrepresentable y por tanto separado de la palabra. Agrupamos las observaciones de Freud en ocho apartados. Se subraya la importancia de la voz para que resuene en el cuerpo, generalmente comprometida con los afectos y desligada en un primer tiempo de la palabra. La voz será indispensable para la constitución de la pulsión.
\end{abstract}

Palabras clave: voz, juicio de atribución, juicio de existencia, escisión entre voz y palabra, pulsión, alucinación auditiva.

\section{Resumo}

O objetivo deste artigo é mostrar o progresso de uma investigação sobre a voz. Aqui se trata de apresentar algumas das contribuições e observações clínicas de Freud. Como ele não considerou a voz um conceito ele oscila entre a noção de voz como um fenômeno e a noção de voz como um resto irrepresentável e, portanto, separado da palavra. Agrupamos as contribuições de Freud em oito seções. Se enfatiza a importância da voz enquanto ressonante no corpo, geralmente comprometida com os afetos e separada, em um primeiro momento, da palavra. A voz será essencial para a formação da pulsão.

Palavras chave: voz, julgamento de atribuição, clivagem entre a voz e a palavra, julgamento de existência, pulsão, alucinação auditiva.

\section{Abstract}

The goal of this text is to highlight the progress of an investigation on voice. This is exposing some of the clinical Freud's observations. As he did not theorize this notion, he oscillated between considering the voice sometimes as a phenomenon and in other occasions as a remainder, and therefore impossible to be represented. The voice will remain separated from the word. Freud's contributions were classified into eight sections. The importance of voice is emphasized because it resonates in the body; it is usually committed with the affections and detached from the word in the first time of the judgment. The voice will be essential for the formation of the drive.

Keywords: voice, judgment, split between voice and speech, drive, auditory hallucination.
Recebido em: 08/07/2013

Revisado em: $15 / 06 / 2015$

Aceito em: 22/06/2015

\begin{abstract}
1) Psicoanalista. Es licenciada y maestra en psicóloga clínica por la Universidad Autónoma de Querétaro y doctora en Antropología por la Universidad Nacional Autónoma de México. Es docente e investigadora de la Facultad de Psicología de la Universidad Autónoma de Querétaro.
\end{abstract}




\section{Resumé}

Le but de cet article est de mettre en évidence les progrès d'une recherche sur la voix. Dans ce cas, on expose quelques-unes des observations cliniques de Freud. Comme il n'a pas conceptualisé la notion de la voix, Freud oscille entre la notion de la voix comme un phénomène, objective, et la notion de la voix comme un reste et donc irreprésentable, séparé de la parole dans un première temps. On regroupés les apports de Freud en huit sections. On remarque l'importance de la voix parce qu'elle résonne dans le corps, généralement engagé avec les affections et détaché de la parole dans un premier temps du jugement. La voix est essentielle pour la constitution de la pulsion.

Mots-clés: voix, jugement d'atribution, jugement d'existence, clivage entre la voix et la parole, pulsion, hallucination auditive.

¿Qué es la voz para Freud? No es una noción que él haya teorizado. El interés de ir a buscar sus observaciones y aportes deriva de la formalización que hizo Lacan de la voz como un soporte del objeto a causa de deseo. Lacan fue quien acuñó el término pulsión invocante y quien avanzó en la relación de la voz con el goce. Extraje exclusivamente aquello que se diferencia de la palabra. Freud oscila entre (1) considerar la noción de voz como fenómeno (sonoro o insonoro), (2) considerarla como algo que puede separarse de la palabra (hipnosis o canto), (3) La versión castellana traduce pasajes de textos de Freud con el término "voces" para referirse a palabras, frases o fragmentos de frases, dichas por los padres y otros, acepción en la que no me detendré en este texto; y (4) considerar las vicisitudes de la voz, por un lado como un resto inasimilable producido por la primera organización psíquica, y otra parte de la voz que se incorporará para que el niño tenga su propia voz. La cuarta perspectiva es la de mayores consecuencias. Lo planteado en el punto cuatro es una construcción resultado de hacer dialogar algunos textos de Freud. Por limitaciones de espacio sólo me referiré aquí a ocho aportaciones.

Voz viene del latín vox, vocis, para la lengua castellana y según el Diccionario de la Real Academia es un sonido que el aire, expelido de los pulmones, produce al salir de la laringe, haciendo que vibren las cuerdas vocales. Para el psicoanálisis la voz trasciende la dimensión sonora. La opinión de los psicoanalistas se divide en este punto. Quedará en reserva discutir, para el futuro, esta cuestión porque rebasa los propósitos de este trabajo. Al final de este artículo emitiré mi opinión sobre si la voz tiene o no significación, como una conclusión provisional, y exclusivamente en relación con Freud.

La voz es un recurso fundamental de la subjetivación y es un vehículo de la comunicación de los afectos. Es difícil disfrazar un afecto en la voz. Ya sea cólera, tristeza, angustia o júbilo, producen brillantez u opacidad, variación en el timbre, en el volumen, en el ritmo, y transmiten a otro algo que no está en el decir, y más allá de la voluntad de quien la emite. Su carácter evanescente es lo que hace que se preste para expresar lo inconsciente y para dejar algo en el enigma, y en el equívoco.

En mi opinión el punto nodal de las aportaciones de Freud es el juicio pues permite organizar sus otros hallazgos. El juicio opera en dos tiempos. El primero que produce un resto de la voz del semejante, inasimilable, y el segundo, otra voz que podrá ser simbolizada y enlazarse a la palabra. La revisión de esta importante cuestión de la voz, relativa al juicio, se debe a los aportes de Vives (2001) con quien encontré algunas coincidencias. He buscado no hacerle decir a Freud cosas que no dijo. Pero sí extraer consecuencias de sus observaciones y hallazgos.

\section{De la escisión entre voz y enunciado en la sugestión e hipnosis}

Freud destacó tempranamente el carácter seductor que la voz tiene y la eficacia simbólica efímera del ensalmo, de decisiva influencia en la sugestión y en la hipnosis. Advirtió que la voz puede comunicar una intención distinta, a la frase de la orden hipnótica, por el tono. Si el hipnotizador no está seguro de hipnotizar lo delatará su voz, aunque la orden diga otra cosa. Entonces la hipnosis no se logrará. La voz entonces comunica algo que va más allá del enunciado, y con frecuencia puede revelar una contradicción o simplemente un mensaje muy distinto a lo dicho con palabras (Freud, 1891/1986a, p. 137). Y más tarde daría argumentos para pensar que esa separación entre la voz y la palabra es consecuencia de ser sujetos divididos. Voz y enunciado juntos constituyen una enunciación.

Para el infante la voz del adulto sin palabra (como grito, interjección, gemido, etc.) puede permanecer como enigma, como huella no ligada. Y estas experiencias tempranas con la voz del adulto que indujeron estados afectivos se reactivan en la hipnosis y en la masa. El hipnotizado y el miembro de una masa regresionan a momentos de desvalimiento (1921/1984d, pp. 111, 116-117).

Más de dos décadas después Freud volvería a la cuestión de la hipnosis y la sugestión para analizar el fenómeno de la masa como una entidad que sufre regresiones a fases de la vida de un gran desamparo y luego de una gran dependencia y que por eso demanda un líder que hable por ella. La voz del líder y lo que ella transmite, devienen recursos indispensables en la relación con una masa.

La situación es la misma que si el hipnotizador hubiera dicho a la persona: «Ahora ocúpese usted exclusivamente de mi persona; el resto del mundo carece de todo 
interés». Desde el punto de vista técnico, sin duda, sería inconducente que el hipnotizador pronunciara esas palabras; ellas arrancarían al sujeto de su actitud inconsciente y lo estimularían a la contradicción consciente. Pero al par que el hipnotizador evita que el pensar consciente del sujeto se dirija sobre sus propósitos, y este se absorbe en una actividad a raíz de la cual el mundo no puede menos que vaciársele de interés, ocurre que inconscientemente concentra en verdad toda su atención sobre el hipnotizador, se entrega a la actitud del rapport, de la trasferencia, con el hipnotizador. (Freud, 1921/1984d, p. 120)

A propósito de la extraordinaria transformación que un individuo pensante sufre al estar en una masa Freud reflexiona sobre la identificación. La identificación tiene una función de lazo vinculado al ideal del yo y está implicada con la inducción recíproca de los afectos (Freud, 1921/1984d, p. 80). Esto nos remite a una de las razones de la regresión. Desde el Proyecto de una psicología para neurólogos (Freud, 1950/1986g) consideró que los afectos eran un resto de las vivencias de satisfacción y dolor. ¿Acaso puede haber ideal del yo sin una voz que actualice para el niño lo que se espera de él? Esa estructura de la relación entre un yo y un ideal del yo se recrea en la masa. La eficacia del dominio sería difícil pensarla si el líder sólo tuviera enunciados sin voz. La película El discurso del Rey dirigida por Hooper (2010), ofrece claramente la evidencia de que un gobernante, por tartamudear, no puede hablarle a su pueblo, no hace lazo en acto, no se puede constituir propiamente en un líder. Podrá transmitir un discurso a través de terceros, pero ya no tiene el mismo efecto.

\section{De la voz y la pulsión.}

La importancia que tiene para el infans la voz del semejante se puede deducir de su texto matricial: En el Proyecto del 1895 [1950]. Freud no destaca la voz de manera explícita, pero es uno de los rasgos del complejo perceptivo del semejante y seguramente el más importante. Cuando se refiere a esos rasgos dice "registros visuales, auditivos y de movimiento" (Freud, 1950/1986g, p. 377). De ese complejo perceptivo extraemos que la palabra y voz de la madre van a formar parte de la acción específica una vez que ella ha localizado lo que cancela la tensión del infante.

La inervación lingüística es originariamente una vía de descarga que opera a modo de una válvula para $\psi$, a fin de regular las oscilaciones de Q 'n; es un tramo de la vía hacia la alteración interior, que constituye la única descarga mientras la acción específica esté todavía por descubrirse (...) Dicha vía cobra una función secundaria, pues llama la atención del individuo auxiliador (por lo común, el objeto deseo mismo) sobre el estado anhelante y menesteroso del niño, y a partir de entonces sirve para el entendimiento \{comunicación\}, siendo así incluida dentro de la acción específica. (Freud, 1950/1986g, p. 414)

El término que emplea Freud y que se tradujo como entendimiento es Verständigung. Otras acepciones de dicho término son: notificación, comunicación, recepción. La voz de la madre va a ser un objeto a incorporar junto con el pecho. La voz es lo más cercano a la pulsión oral. La incorporación del pecho provee el molde de la incorporación de la voz. El llanto, como esbozo de su voz, está dirigido a la madre, o como dice Freud "al semejante que auxilia al infante". La voz materna es un objeto de primer orden para la constitución de la pulsión.

Una primera organización sexual pregenital es la oral o, si se prefiere, canibálica. La actividad sexual no se ha separado todavía de la nutrición, ni se han diferenciado opuestos dentro de ella. El objeto de una actividad es también el de la otra; la meta sexual consiste en la incorporación del objeto, el paradigma de lo que más tarde, en calidad de identificación, desempeñará un papel psíquico tan importante. (Freud, 1905/1978b, p. 180)

En el Manuscrito $G$ (Freud, 1895/1986c, p. 242) ofrece su único esquema de la pulsión al que le pone tres puntos que organizan un circuito y no un concepto dicotómico fronterizo entre cuerpo y psique, como generalmente se le ha transmitido. Si hay tres puntos del circuito pulsional, el que es organizador es el objeto que procura el semejante auxiliador con su "acción específica” (Freud, 1950/1986g, p. 362). Esta acción específica no es un contexto del objeto es un factor constituyente del mismo, acción por excelencia diferenciadora y soporte del sistema simbólico. Del semejante provendrá voz, mirada, nutrientes y libido (que lo coloca como "His Majesty the baby") para la experiencia de satisfacción, así como también, tendencias adversas a la misma satisfacción.

Freud plantea el carácter especular en que la voz se pone en juego, así sea bajo la forma del grito. Cuando digo especular, me refiero a que Freud considera que el niño asocia el grito del adulto con el suyo propio, y le hace recordar vivencias dolorosas. “(...) por eso se puede hablar de un valor imitativo de una percepción" (Freud, 1950/1986g, p. 379), una suerte de mimetismo, lo mismo dice de los movimientos corporales. Esa alteridad de la presencia del otro no es alteridad aún para el niño pero se constituirá más adelante. El grito del adulto le hace recordar vivencias displacenteras asociadas a su propio grito (Freud, 1950/1986g, p. 377). Es un esbozo del transitivismo. En un inicio, el grito del infante es una reacción refleja, pero para la madre es la voz del niño, gracias a eso, el grito tendrá estatuto de llamado para invocar y para hacerse escuchar. 
Para que el infante tenga su propia voz, para hacerse escuchar, es preciso haber escuchado, en un tiempo lógico anterior, la voz de su madre. Luego se pondrán en juego para el infante, la pulsión escópica, mirar-ser mirado, la pulsión de comunicar (Freud, 1905/1986j, p.137), la de ser reconocido; esta consiste en llamar, hacerse escuchar, ser escuchado, estas operaciones no las hace el infante solo, es un circuito pulsional con su madre. La idea de un circuito pulsional es originalmente de Freud. Su esquema está direccionado con flechas (Figura 1).

Si seguimos fielmente el gráfico de Freud, la pulsión tiene tres registros, no dos, (Drang, Vorstellung y Objeckt). Esa tercera localización (Objeckt) comprende voz, palabra,

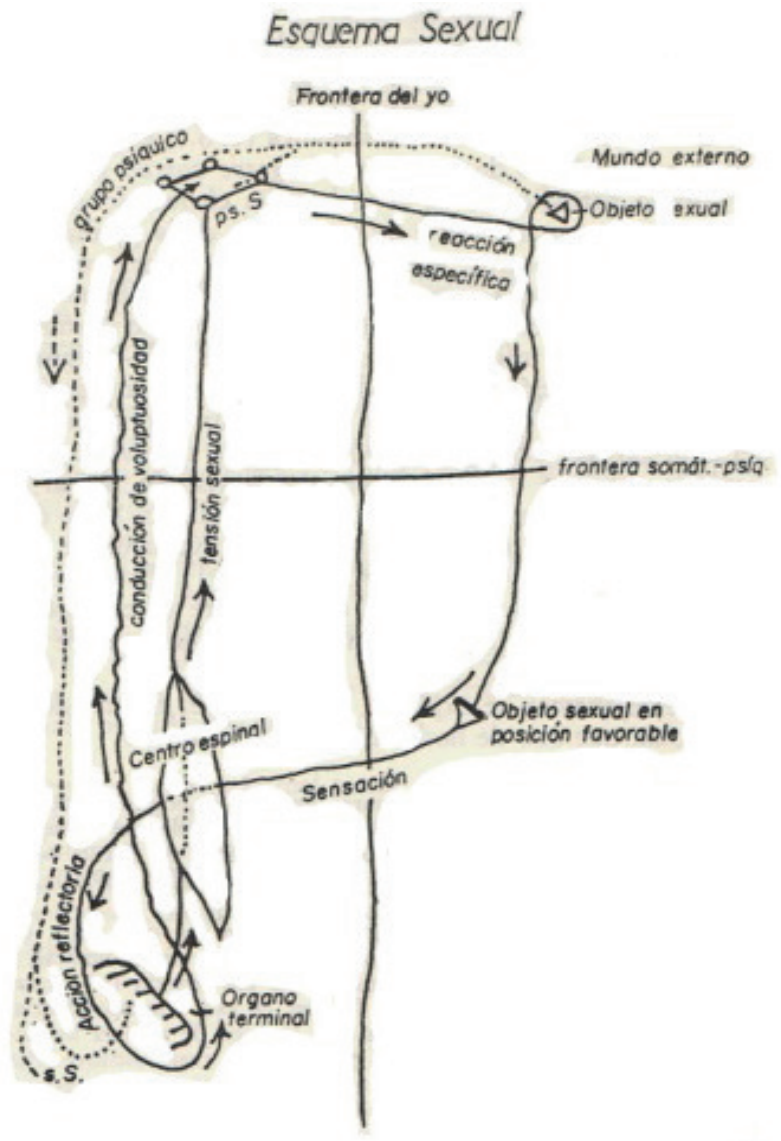

[En el original, todas las flechas están en tinta roja, excepto la punteada que se halla arriba a la izquierda.]

Figura 1. Esquema de la pulsión (Freud, 1895/1986c, p.242)

mirada, y lo que la madre le entrega como don, es la fuente de todo el circuito. Para que la voz del adulto deje de ser un mero fenómeno y adquiera la cualidad repetitiva que organizará la posibilidad de que él tenga voz, se requiere la operación del juicio. Más tarde integró la pulsión de muerte, a la que considerará silenciosa; participará como repetición en la pulsión de reconocimiento por su mezcla con eros
(Freud, 1919/1984c, pp.54, 60; 1923/1984e, p. 42).

\section{El juicio como operación que separa una voz como resto y otra que se enlazará a la palabra.}

Freud consideró que el juicio es la operación que funda el psiquismo y se produce en dos tiempos. Su reflexión sobre el juicio también la realizó en dos tiempos: (1) el Proyecto de 1895 y (2) en La negación de 1919. Del constante contraste entre la percepción del adulto y las vivencias de dolor y satisfacción del infante, logrará separar el complejo perceptivo del semejante en dos partes y operar una distinción yo-no yo.

Y así el complejo del prójimo se separa en dos componentes, uno de los cuales impone por una ensambladura constante, se mantiene reunido como una cosa del mundo, mientras que el otro es comprendido por un trabajo mnémico, es decir puede ser reconducido a una noticia del cuerpo propio. (Freud, 1950/1986g, p. 377)

Al componente permanente, Freud le llama "neurona a", también "complejo sujeto", o Das Ding traducida como "cosa del mundo". Consiste en un conjunto de neuronas constantemente investidas, son restos que se sustraen de la apreciación judicativa, no pueden ser comprendidos por huellas mnémicas (Freud, 1950/1986g, pp. 368, 377, 379 y 432). Das Ding es entonces irrepresentable. Al componente variable, le llama "neurona b", actividades o predicados, son comprendidos por un trabajo mnémico y remitidos a una noticia del propio cuerpo, sí pueden ser comprendidos por un trabajo de pensar. También plantea que la totalidad de investiduras $\psi$ (es decir de memoria), en que un componente permanente se ha separado del componente variable, es a lo que denominará “yo" (Freud, 1950/1986g, pp. 368, 373, 377 y 432); podemos entender entonces que el yo comprenderá investiduras de memoria excepto en su núcleo o Das Ding.

¿Qué es lo perceptible del semejante? Freud no hace explícito el término voz, pero sí se refiere a los rasgos perceptivos del semejante, entre ellos los auditivos, visuales y de movimiento. Comprende su imagen, especialmente su rostro y manos, su voz (tono, timbre, volumen, acento), su mirada, su tacto, su "holding" y, agreguemos nosotros, sus afectos. Algo de la voz materna será simbolizado y algo pertenecerá al Das Ding. La voz puede representar algo del objeto y del propio dolor de su cuerpo que el eyecta como un no-yo "Toda vez que ante el dolor no se reciban buenos signos de cualidad del objeto, la noticia del propio gritar sirve como característica del objeto." (Freud, 1950/1986g, p. 415) Ese dolor puede ser un malestar físico, o puede ser un afecto displacentero producido por los propios afectos de la madre u otro adulto. De esto se infiere que la voz como 
el cuerpo es transitivo; primero el grito formará parte del no-yo, pero en el segundo tiempo del juicio integrará lo que había eyectado.

La voz del semejante sustraída de todo registro mnémico será su forma más arcaica (Unheimlich) y desligada por supuesto de la palabra. El recuerdo del infante de la voz del adulto va a tener un carácter alucinatorio durante un tiempo prolongado, mientras no se pone en marcha el proceso secundario (Freud, 1950/1986g, p. 430). La voz desligada de la palabra generará motivos compulsivos y puede ser un aspecto que resignifique un trauma, como es el caso de la viñeta referida en el Proyecto: la joven que tenía miedo de entrar sola a una tienda. Es la risa (como voz más la sensación corporal) la que detona la resignificación y conecta la primera escena con la segunda; risa ligada a la sensación sexual y al sentimiento de sentirse atraída. La voz desligada de la palabra estará sustraída de la simbolización es un resto perceptivo, al igual que los afectos que son restos de una vivencia ya sea de satisfacción o de dolor (Freud, 1950/1986g, p. 366). Lo no ligado será materia prima de la fantasía que aparecerá hacia el sexto mes de vida (Freud, 1897/1986f, p. 285). Se conforma con restos cruzados de cosas oídas y de cosas vistas. Es decir, se creerá haber visto lo que en realidad se escuchó y se creerá haber oído lo que en realidad se vio. La mirada entonces puede subrogar la voz y viceversa.

En el primer tiempo del juicio o juicio de atribución, "El yo-placer originario quiere, introyectarse todo lo bueno, arrojar de sí todo lo malo (Freud, 1925/1984g, p. 254). $\mathrm{Y}$, en el juicio de existencia, “(...) no sólo es importante que una cosa del mundo (objeto de satisfacción) posea la propiedad 'buena', y por tanto merezca ser acogida en el yo, sino también que se encuentre ahí, en el mundo exterior, de modo que uno pueda apoderarse de ella si lo necesita" (Freud, 1925/1984g, p. 255). El infante recompone lo que originalmente había eyectado y reconoce que el semejante auxiliador es, a la vez que nutriente y proveedor de satisfacción, también es frustrante y ocasionador de dolor. El clivaje se produce de ambos lados, del lado del infante y del lado del semejante. Lo no simbolizado de la voz y la mirada maternas, de alta significatividad, en el primer tiempo del juicio, permanecerán sin ligadura con un carácter enigmático e incomprensible y alimentarán la fantasía. El segundo tiempo del juicio recogerá otros aspectos de voz y mirada que sí estarán ligados a palabras.

\section{Síntomas que toman como lugar de expresión los fenómenos relativos a la voz o la voz misma.}

Freud descubrió tempranamente en su clínica el papel de la voz en los síntomas histéricos, sea la tartamudez, la afonía, los tics, la tussis hysterica, la inhibición espástica, el chasquido, el grito, y distintos tipos de sordera psicógena.
Muestra esto en varios casos: Emmy von N, Anna O, Sra. P., Rosalía, Cecilia M, Cäcilie, Dora, y otros que refiere sin nombre. Anna O. no reconocía en sus estados hipnoides la voz de Breuer y sólo se aseguraba de estar frente a él hasta que le tocaba las manos (Freud, 1893/1985a, p. 55). En otros momentos su mutismo involuntario y sus tensos ensayos para hablar, no lograban producir sonido alguno (Freud, 1893/1985a, p. 50). Sus estados de angustia, a veces, se expresaban como afasia histérica.

En otras ocasiones el síntoma que recaía sobre la voz no alcanzaba la propia voz sino la de quienes la rodeaban $\mathrm{y}$ en particular la de Breuer, para quien tuvo una sordera selectiva. A partir de lo observado por Breuer, la voz es un objeto separable de quien la emite y puede faltar, los afectos no son indiferentes en este mecanismo. Ella presentaba distintos tipos de sordera: no oír, no comprender cuando hablan, no oír ruidos que la atemorizan, ponerse sorda por mucho escuchar y espiar (Freud, 1893/1985a, p. 60). Ésta última da una clave de las otras por el efecto traumático que produce la voz en la formación de la fantasía (y particularmente por escuchar demasiado lo que no le concierne). La voz siempre transmite algo más, enigmático, no explícito. Sordera o incapacidad de hablar, la voz emerge ahí como el objeto pulsional en cuestión. Es frecuente que las pacientes histéricas no puedan hablar en periodos de crisis, o que cualquier ser humano interrumpa su decir cuando está al borde del llanto (que es otra forma de la voz), la angustia u otra intensa manifestación afectiva.

En el caso de Rosalía H. (Freud, 1895/1985b, p. 182), se trataba de una conversión histérica que se expresaba en la joven cantante. Su voz no le obedecía en ciertas escalas. Sentía ahogo y opresión en la garganta y las notas sonaban estranguladas. La perturbación era intermitente. El análisis mostró que su tío había abusado sexualmente de ella cuando quedó huérfana. Ese tío maltrataba a su mujer y a sus hijos; y al morir la tía, ella protegió a los niños. Sofocando su odio y desprecio por el tío, se generó la opresión en la garganta. Así se consolidó el vínculo entre el cantar y la parestesia histérica. La sofocación de la expresión del odio parece ser el factor desencadenante. Si hay una pasión que resiste a la simbolización es el odio. Otra vez tenemos aquí un intenso afecto que afecta la voz.

La pertinaz tussis hysterica es otra forma de la voz. Freud se ocupó de ella en Psicología de las Masas para referirse a la identificación en un internado: donde una joven con tos recibe una carta de un amado secreto; luego las jóvenes que son sus compañeras, tienen tos, revelando así el deseo de estar en la misma situación. La elección de objeto regresa hasta la identificación que, en este caso, es parcial y limitada pues toma un único rasgo (Freud, 1921/1984d, p. 101).

La tos como voz histérica confiesa su elección identificatoria, su lugar en la escena de su fantasía, aunque se desconozca lo que está en juego. La afonía de Dora 
le reveló el peso que tenía en ella una voz para hacerse escuchar, pues si el Sr. K no estaba, hablar perdía todo interés. Así la afonía aparecía en ausencia y revelaba su amor por él (Freud, 1905/1978a, pp. 35-36). El silencio pone de relieve la importancia de la voz como suscitada por el amado. En cambio la tos de Dora parecía estar dirigida al padre y comprometida con una fantasía oral de realización sexual (Freud, 1905/1978a, p. 43). Freud no habló de pulsión invocante (término que Lacan propone) pero sí habló de pulsión de ser reconocido (Freud, 1919/1984c, p. 39). Es con la voz que el ser humano busca hacerse escuchar, ser reconocido.

Emmy von N., célebre por más de una razón, presentó síntomas en los que se ponía de manifiesto el compromiso con la voz: la inhibición espástica y el tartamudeo, y que en ella no reconoció un símbolo mnémico propiamente sino la inhibición convulsiva del acto de hablar (Freud, 1895/1985c, p. 111). Destaca Freud que lo que detona los motivos compulsivos es lo que no se puede traducir (Freud, 1896/1986e, p. 277).

\section{La voz en la asociación libre como vía de acceso a la verdad del analizante}

El carácter evanescente de la voz y su extraordinaria agilidad para hacer variar una letra y enlazarse a otras sílabas de las palabras son productores de sentidos. La voz permite el paso de un lapsus, y de cualquier enunciación que dice más de lo que pretende decir y, que se pretende decir de un modo y se escucha de otro. Sin la voz del paciente y del analista no hay psicoanálisis, y esto tuvo consecuencias para el método pues así nació la asociación libre y como consecuencia la transferencia. La voz permite el paso de significantes. Y aunque Freud no propuso esta noción sí localizó significantes en sus casos. Al menos tenemos evidencia explícita de los significantes escuchados con Elizabeth de R. (Freud, 1895/1985b, pp. 165-167). Freud descubrió que lo inconsciente desfila por medio de palabras fragmentadas, por fonemas que la voz vehiculiza en la enunciación. Freud estaba alerta a las inflexiones, tonos, matices, ritmo y volúmenes de la voz de sus pacientes que, en ocasiones se ponen al servicio de la defensa, y en ocasiones le imprimen al decir una significación particular. Cuando relata sus casos no deja de describir esta gama de expresiones que dan cuenta de la vida afectiva "(...) Esto nos lleva a aquellas perturbaciones del habla que ya no se pueden caracterizar como deslices porque no afectan a las palabras individuales, sino al ritmo y la pronunciación del dicho entero; por ejemplo, el balbuceo y tartamudeo que se producen en estado de turbación" (Freud, 1901/1986i, p. 102).

En uno de sus llamados escritos "técnicos", (Freud 1912/1986m) habla de lo que singulariza a la escucha analítica. No se trata sólo de oír las palabras. Escuchar supone algo más, algo que está entre palabra y voz; y aunque la metáfora que emplea no es muy afortunada, sin embargo deja ver una intuición de Freud para mostrar ese más allá de la palabra:

(...) el médico (...) debe volver hacia el inconsciente emisor del enfermo su propio inconsciente como órgano receptor, acomodarse al analizado como el auricular del teléfono se acomoda al micrófono. De la misma manera en que el receptor vuelve a mudar en ondas sonoras las oscilaciones eléctricas de la línea incitadas por ondas sonoras, lo inconsciente del médico se habilita para restablecer, desde los retoños a él comunicados de lo inconsciente, esto inconsciente mismo que ha determinado las ocurrencias del enfermo. (Freud, 1912/1986m, p. 115)

Lo inconsciente no sólo habla con la palabra, habla también más allá de ella gracias al auxilio de la voz. La voz produce deslizamiento entre los fonemas, entre otros efectos. Se trata en suma de escuchar lo que escapa al pensamiento de vigilia regido por el proceso secundario.

\section{Sin voz no hay actualización del legado transgeneracional.}

Como ya se mencionó en el apartado dos, la incorporación es precursora de la identificación. La función de la voz es unir el cuerpo del niño con una lengua (la de su región, etnia o país) y con el discurso transgeneracional. Se incorpora lo que hace falta. El infante incorpora el seno materno, el alimento, pero también la voz. Un legado se organiza en torno a una falta. Lo que inserta al infante en una genealogía es “(...) la identificación primera y de mayor valencia, del individuo: identificación con el padre de la prehistoria personal (...)" (Freud, 1923/1984e, p. 33), registro primero del superyó que es el núcleo del yo (Freud, $1927 / 1986$ p, p. 160). La prehistoria es altamente singular, de lo contrario, toda la humanidad tendría la misma identificación. No se trata del padre totémico, sino de aquel que es transmitido en el mito familiar. Freud empleó el término prehistoria, (1) a veces, como sinónimo de filogénesis, (2) a veces como sinónimo de primera infancia, anterior a la latencia, y (3) en el caso del Hombre de las Ratas, apreciamos otro modo de entender la prehistoria: está ligada al modo como el padre de este paciente decide su matrimonio, y al discurso familiar que presiona al hijo (Ernst Lanzer) a repetir lo que el padre hizo: casarse por interés económico. (Freud, 1909/1986k, p.156)

Consideremos el mito del padre de la horda como un recurso lógico e ilustrativo. Como bien destaca Vives (2001, pp. 160-161) el tema de la identificación en el advenimiento de la propia voz está claramente explícito 
en su texto Tótem y Tabú. Ahí indica que el lazo, con el padre de la horda "(...) no es otra cosa que la vida de la víctima, víctima que mora en su carne y en su sangre (...)" gracias al banquete sacrificial (Freud, 1913/1986n, p. 140), tiempo de la incorporación luego de la cual vendría una “(...) identificación que pasaría en parte por una imitación de esencia vocal (...)" cuando los miembros del clan gritan la onomatopeya del animal totémico pretendiendo hacerse reconocer como hijos del muerto (Vives, 2001, p.160). Muerto el padre, el miembro de la fratría puede usar su voz para invocar. Es necesario haber perdido un objeto para acceder a la propia voz. La doble presencia del padre, por el sacrificio primitivo, como dios y luego como tótem (Freud, $1913 / 1986$ n, p. 149) corresponden al primer y segundo tiempos del juicio respectivamente.

Freud estableció una relación lógica entre el totemismo y el Edipo. El superyó encarnaría la ley que prohibiría la repetición del asesinato. Se trata de una instancia que encarna la ley y la filiación. El superyó, en su primera inscripción, será una instancia necesaria para hablar. Llama la atención que Freud, en El yo y el ello, emplee como sinónimos tanto al superyó como al ideal del yo. En ese texto le da un lugar importante a la cuestión de la voz al localizar en su aparato psíquico (segunda tópica) un casquete auditivo o calota acústica (Hörkappe) (Freud, 1923/1984e, p. 26) sobre el lado izquierdo, del mismo lado donde ubicará al superyó hasta un esquema de 1933 (Freud, 1933/1986q, p. 73) (figura 2), pues el superyó está constituido por restos de cosas oídas. Por eso en su segunda tópica la relación entre el ello y el superyó es muy cercana y claramente dice que el superyó hace resucitar figuras yoicas más antiguas (Freud, 1923/1984e, p. 40), mismas que no podrían resucitar sino por una voz que las actualiza.

Freud plantea que el superyó es un subrogado del ello (Freud, 1924/1984f, p. 172) y que clínicamente es difícil de reconocer la diferencia entre ambos. El ello es lo no subjetivado, el superyó en cambio, se teje a partir de una primera identificación. Tanto la idea de un ello que alberga innumerables existencias-yo, como la segunda de que el superyó es un sustituto del ello, serían imposibles sin la voz como objeto pulsional por excelencia. La voz actualiza lo "heredado". El superyó procura un recorte singular distinto para cada integrante de una familia. Esta perspectiva interroga también por supuesto la noción de ello como reservorio pulsional originario ${ }^{1}$, pues si la pulsión es altamente singular no habría un ello dado desde el origen, si entendemos que la pulsión supone una trabazón corporal que se produce gracias a las vivencias. Una conclusión que emana de esta reflexión es que, entonces, el modo de recoger un legado generacional de naturaleza discursiva, que comprende también lo que está a medio decir gracias a la voz, ocurre inicialmente por vía del superyó y luego de la pulsión. Y no del ello como instancia a menos que entendamos a éste como sede del mito familiar.

\section{La voz, lo mal-escuchado o incomprendido y la formación de la fantasía.}

El hallazgo de Freud sobre la participación de la voz en la fantasía es muy temprano. Se lo encuentra en sus cartas a Fliess y en sus manuscritos. Las fantasías se forman con restos de cosas oídas y mal comprendidas, que fueron resignificadas con posterioridad. Lo oído, gracias a la voz,

1 Esta noción es solidaria con la idea de "pulsiones congénitas" de las que Freud habla en su apartado VI de "Más Allá de principio del placer" que es el menos psicoanalítico de todos los apartados de ese texto pues no se apoya en lo que encuentra clínicamente sino en trabajos de biólogos. Aunque ciertamente Freud osciló entre esta perspectiva más filogenética y considerar al ello como un "ello que habla en el sujeto" en el sentido en que lo propuso Groddeck.

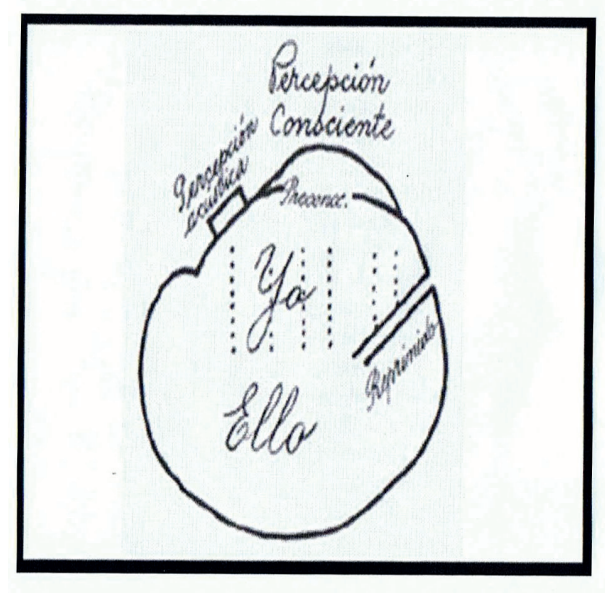

1923

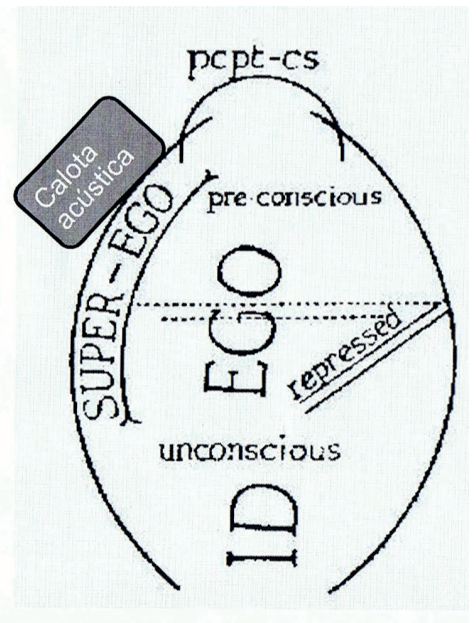

1933

Figura 2. Segunda tópica (Freud, 1923/1984e, p.26) (Freud, 1933/1986q, p. 73) 
inscribirá luego la palabra cuando ya haya representaciones y proceso secundario. Pero sin la voz no habría forma de que se vinculara el cuerpo con el lenguaje.

La hiperestesia auditiva de algunos insomnes adultos está relacionada con épocas muy tempranas de la infancia, cuando el sujeto cohabitaba en la misma habitación de los padres y tenía ocasión de ver mucho y oír mucho más, cuando aún no había alcanzado la capacidad de hablar. Así, con la primera polución nocturna, se resignifican esas fantasías onanistas con el tiempo primero traumático de la escena primaria, resultado de lo cual se produce un insomnio como formación de compromiso: por un lado, una defensa contra esas percepciones nocturnas y por otra, un deseo de conservar la vigilia en que pudo espiar esas impresiones (Freud, 1939/1986r, pp. 75-76). Entonces uno de los efectos traumáticos de la fantasía de la escena primaria retorna en algunas formas de insomnio. Traumático porque no se puede ligar. La voz en la escena primaria no tiene como función principal ser vehículo de la palabra sino del goce (gemido, llanto, y vocalizaciones que no tienen sentido para el infante). El infans estuvo incluido en esa escena negligentemente como "testigo", a la espera de que luego las palabras de los padres y sus intersticios, pudieran transmitir qué querían de él.

La conjunción de cosas vivenciadas, sentidas y oídas se expresa también bajo los fenómenos conocidos como: "dejà vecu” (lo ya vivido), "dejà vu” (lo ya visto), y "dejà raconté" (lo ya platicado), "dejà entendu" (lo ya escuchado), dejà sentí (lo ya sentido). Freud lo explica así: En un momento anterior hubo una percepción inconciente, que sólo ahora bajo el influjo de una impresión nueva reanima la anterior y alcanza la conciencia, pero no aún el sentido que está en juego. Esta idea la tomó de Grasset (Freud, 1914/ 1986o, p. 208) y la constató en su clínica. Estos hechos que se presentan bajo este fenómeno son de gran significatividad (Freud, 1914/1986o, p. 209). Se relacionan con fantasías insusceptibles de conciencia. Estos fenómenos constituyen un retorno al primer tiempo del juicio donde el clivaje aún no se producía y el infante reunía en su yo lo bueno y expulsaba lo malo.

\section{Las voces en la alucinación auditiva.}

Sobre la alucinación se encuentran en la obra de Freud muy pocas referencias. Y las alucinaciones auditivas que tuvo ocasión de referir eran de sus histéricas y de algunos casos de paranoia que atendió en su juventud, o su reflexión sobre el caso Schreber, donde analiza los enunciados del delirio sin la voz, puesto que analiza un documento escrito.

Afirmaba Freud que persona sana sólo hace resonar quedamente lo que ha escuchado, en cambio la excitabilidad anormal recrea lo oído de modo alucinatorio como una sensación auditiva real. Plantea que no todos los fenómenos de la histeria son ideógenos, pues no siempre tienen que ver con representaciones-palabra (Freud, 1895/1985d, p. 202). El primer registro de la voz escapa a la representaciónpalabra; es signo de percepción. Los tonos de voz inducen determinados afectos como en el caso de la Sra. P (Freud, 1896/1986h, p. 179). Freud tenía en ese tiempo la hipótesis de que la alucinación se producía, o bien porque el paciente había reprimido el afecto, o bien porque no había representación de ello y que retornaban como alucinaciones de voces que le hacían reproches. En el manuscrito K dirigido a Fliess se refiere a las alucinaciones auditivas en la paranoia.

Por tanto, el síntoma primario así formado es la desconfianza (susceptibilidad frente a los demás). Mediante este proceso, un auto-reproche queda privado de todo crédito. Podemos presumir que existen distintas formas, según que sólo el afecto haya sido reprimido por proyección o también se haya reprimido el contenido de la vivencia. En tal caso, el retorno comprenderá únicamente el afecto penoso o, junto con él, el recuerdo correspondiente. En el segundo caso, único que conozco con cierta precisión, el contenido de la vivencia retorna como una simple ocurrencia o como una alucinación visual o sensitiva. El afecto reprimido parece retornar invariablemente en la forma de alucinaciones con percepción de voces. (Freud, 1896/1986d, p. 267)

En 1915 planteó que los afectos no se reprimen (Freud, 1915/1984b, p. 174). En cualquier caso, los afectos están comprometidos con la voz, y específicamente, según observó en la Sra. P, con el tono de voz.

En sus Estudios sobre la Histeria planteó que la alucinación consiste en un pensamiento sonorizado y que en el pensar normal se escucharía esa voz des-sonorizada (Freud, 1895/1985d, p. 203). La representación de una voz, se haría resonar quedamente en el "oído interior", lo contrario es resultado de una excitabilidad anormal, un fenómeno patológico. De las clases con Charcot extrajo una enseñanza: que la fase alucinatoria de las histéricas (denominada attitudes pasionelles) se trataba de la reviviscencia alucinatoria de una escena significativa para la contracción de la neurosis (Freud, 1894/1986b, p. 171). Lo visto y lo oído están ahí combinados de modo particular; es el tiempo de la fijación del trauma. Es fijación de lo incomprensible pues no está ligado a la palabra. Afirmó que la alucinación es un fenómeno que emerge como movimiento regrediente, pues es de los primeros mecanismos que realiza el infante frente a la tensión y la búsqueda de descarga: la alteración interior, expresión de las emociones, berreo e inervación vascular (Freud, 1950/1986g, p. 362). De nuevo destacamos aquí la relación entre la voz y los afectos. La animación del deseo produce inicialmente en el bebé el mismo efecto que la percepción, es decir: una alucinación 
(Freud, 1950/1986g, p. 364). La alucinación es resultado de un estado no ligado también llamado proceso primario.

La voz alucinatoria aparece como algo separado del contexto. Tiene, dice Freud, un lugar equivalente al de la voz del superyó. Sólo que no bajo la forma del tú sino en tercera persona. "La queja de la paranoia muestra también que la autocrítica de la conciencia moral coincide en el fondo con esa observación de sí sobre la cual se edifica." (Freud, 1915/1984a, p. 93)

Por el trabajo de Freud sobre los escritos de Schreber podemos advertir que la voz, como un objeto que puede separarse de quien lo emite, está comprometido con el cuerpo fantasmático. En este caso, es la fantasía de emasculación: "Tales exteriorizaciones son decisivas para situar el delirio de emasculación $y$, así, para entender el caso mismo. Agreguemos que las 'voces' escuchadas por el paciente nunca trataron la trasformación en mujer de otro modo que como una injuria sexual, en virtud de la cual se consideraban autorizadas a burlarse del enfermo." (Freud, 1910/19861, p. 20)

También planteó que la alucinación es de los primeros mecanismos que realiza el infante frente a la tensión y la búsqueda de descarga, y que con frecuencia tenían un carácter imperativo en la paranoia. Este rasgo de las alucinaciones es compartido con la voz del superyó.

\section{Discusión y conclusiones.}

¿Qué era la voz para Freud después de este recorrido? Aunque hemos planteado en algunos apartados inferencias o conclusiones provisionales podemos recapitular aquí las ideas principales. La voz es un componente de la enunciación junto con la palabra. Es de los primeros rasgos perceptivos del semejante que, por la operación del juicio, quedará separado en un resto irrepresentable, no ligado, traumático y que puede retornar como alucinación y una segunda parte que quedará enlazada a la palabra. La escisión entre palabra y voz retornará en todo acto enunciativo. En el caso del normo-hablante lo sonoro sí cuenta en la enunciación, de lo contrario no podríamos escuchar, pero no es la sonoridad sola sino dialogando con la palabra, con el silencio, con el tiempo, con el ritmo, con el contexto del decir, etc. No es el sonido el que aporta la significación, pero tampoco sólo la palabra. Es algo que está en el encuentro entre ambos registros y considerando el diálogo con el silencio y en un contexto específico. En la medida en que hay pulsación, escansión, contraste con silencios hay significación además de sentido. Hablamos porque hay falta, algo queda sin decir, a medio decir, hay enigma. La actualización del legado generacional, ocurre gracias a la voz, pero no a la voz sola sino en tanto es vehículo de la palabra. Por la voz se escuchan y aíslan fragmentos de enunciaciones emitidas por los padres. Es el modo como el infante toma noticia de lo que sus padres quieren de él. En el caso del hipoacúsico su voz no es sonora, está hecha con gestos de su cara y manos que constituyen signos (lenguaje de señas), pero que componen su enunciación por la singularidad con la que cada hipo-acúsico habla al introducir la dimensión temporal. Los hipo-acúsicos también son sujetos de lo inconsciente. Algunos hablarán con lenguaje de señas. Ahí la voz es subsumida por la mirada de quien lo "escucha" y así la posibilidad de percibir un lapsus.

La voz es el objeto de la pulsión que invoca al semejante para ser auxiliado, reconocido, nutrido y amado. La voz es la expresión misma de la invocación, es temporal y por ello evanescente, da cuenta de la condición de ser seres en falta. Es una dimensión singularísima comprometida con los afectos y ligada al lugar de libidinización que asignaron los padres al infante. Es un aspecto central de la enunciación por su costado más real y vehículo de la palabra en el habla, cualquiera que sea su forma (sea en normo-hablantes o en hipoacúsicos). Sin la voz no hay resonancia en el cuerpo, no habría pulsiones. La voz actualiza en una enunciación los enigmas de los deseos de los antepasados, es la vía por la cual la pulsión se teje con la fantasía.

De los hallazgos y observaciones clínicas de Freud sobre la voz, el más importante es: el juicio, que produce la escisión entre palabra y voz y que tiene repercusiones sobre el modo de considerar la pulsión, el superyó y la alucinación. Las teorizaciones que realizó son un punto de partida. Sobre el núcleo del yo Freud dijo cosas diferentes al menos en tres ocasiones: en el Proyecto, El yo y el ello y en El humor. Queda para seguir reflexionando cómo resolver que, en el Proyecto, Das Ding sea el núcleo del yo y por otro lado que en un texto posterior, El humor (Freud, 1927) el núcleo del yo sea el superyó. En ambas teorizaciones Das Ding y superyó son irrepresentables, no ligados, corresponden al juicio de atribución.

Freud aporta luz sobre las voces de la alucinación, más allá de descripciones, si consideramos los dos tiempos del juicio. Las voces hablan en tercera persona, lo que les aporta la cualidad de lo siniestro (Unheimlich), a diferencia de su registro y clivaje del segundo tiempo del juicio que se registrarán como en segunda persona, como un tú que sería la forma del superyó. Ahí la alteridad ya está integrada, en el corazón mismo del yo, gracias a la represión.

\section{Referencias}

Freud, S. (1978a). Fragmento de análisis de un caso de histeria. Caso Dora. In J. Strachey (Ed.), Obra Completa de Sigmund Freud, vol.2. (Originalmente publicado en 1905)

Freud, S. (1978b). Tres Ensayos para una teoría sexual. In J. Strachey (Ed.), Obra Completa de Sigmund Freud, 
vol.7. (Originalmente publicado en 1905)

Freud, S. (1984a). Introducción al narcisismo. In J. Strachey (Ed.), Obra Completa de Sigmund Freud, vol.14, cap.2. (Originalmente publicado en 1915)

Freud, S. (1984b). Lo inconsciente. In J. Strachey (Ed.), Obra Completa de Sigmund Freud, vol.14, cap.5. (Originalmente publicado en 1915)

Freud, S. (1984c). Más allá del principio del placer. In J. Strachey (Ed.), Obra Completa de Sigmund Freud, vol.18, cap.1. (Originalmente publicado en 1919)

Freud, S. (1984d). Psicología de las masas y análisis del yo. In J. Strachey (Ed.), Obra Completa de Sigmund Freud, vol.18, cap.2. (Originalmente publicado en 1921)

Freud, S. (1984e). El yo y el ello. In J. Strachey (Ed.), Obra Completa de Sigmund Freud, vol.19, cap.1. (Originalmente publicado en 1923)

Freud, S. (1984f). El problema económico del masoquismo. In J. Strachey (Ed.), Obra Completa de Sigmund Freud, vol.19, cap.7. (Originalmente publicado en 1924)

Freud, S. (1984g). La Negación. In J. Strachey (Ed.), Obra Completa de Sigmund Freud, vol.19, cap.13. (Originalmente publicado en 1925)

Freud, S. (1985a). Anna O. Estudios sobre la histeria. In J. Strachey (Ed.), Obra Completa de Sigmund Freud, vol.2. (Originalmente publicado en 1893)

Freud, S. (1985b). Elizabeth de R. Estudios sobre la histeria. In J. Strachey (Ed.), Obra Completa de Sigmund Freud, vol.2. (Originalmente publicado en 1895)

Freud, S. (1985c). Emmy von N. Estudios sobre la histeria. In J. Strachey (Ed.), Obra Completa de Sigmund Freud, vol.2. (Originalmente publicado en 1895)

Freud, S. (1985d). Estudios sobre la histeria. Parte teórica. In J. Strachey (Ed.), Obra Completa de Sigmund Freud, vol.2. (Originalmente publicado en 1895)

Freud, S. (1986a). Hipnosis. In J. Strachey (Ed.), Obra Completa de Sigmund Freud, vol.1, cap.10. Buenos Aires, Argentina: Amorrortu. (Originalmente publicado en 1891)

Freud, S. (1986b). Prólogo y notas de la traducción de J. M. Charcot. In J. Strachey (Ed.), Obra Completa de Sigmund Freud, vol.1, cap. 12. Buenos Aires,
Amorrortu. (Originalmente publicado en 1894)

Freud, S. (1986c). Manuscrito G, de las cartas a Fliess. In J. Strachey (Ed.), Obra Completa de Sigmund Freud, vol.1, cap. 15. (Originalmente publicado en 1895)

Freud, S. (1986d). Manuscrito K de las cartas a Fliess. In J. Strachey (Ed.), Obra Completa de Sigmund Freud, vol.1, cap. 15. (Originalmente publicado en 1896)

Freud, S. (1986e). Carta 52 a Fliess. In J. Strachey (Ed.), Obra Completa de Sigmund Freud, vol.1, cap. 15. (Originalmente publicado en 1896)

Freud, S. (1986f). Carta 59 a Fliess. In J. Strachey (Ed.), Obra Completa de Sigmund Freud, vol.1, cap. 15. (Originalmente publicado en 1897)

Freud, S. (1986g). Proyecto de una psicología para neurólogos. In J. Strachey (Ed.), Obra Completa de Sigmund Freud, vol.1, cap. 16. (Originalmente publicado en 1950)

Freud, S. (1986h). Nuevas puntualizaciones sobre la neuropsicosis de defensa. In J. Strachey (Ed.), Obra Completa de Sigmund Freud, vol.3. (Originalmente publicado en 1896)

Freud, S. (1986i). Psicopatología de la vida cotidiana. In J. Strachey (Ed.), Obra Completa de Sigmund Freud, vol.6. (Originalmente publicado en 1901)

Freud, S. (1986j). El chiste y su relación con lo inconciente. In J. Strachey (Ed.), Obra Completa de Sigmund Freud, vol.8. (Originalmente publicado en 1905)

Freud, S. (1986k). A propósito de un caso de Neurosis Obsesiva. In J. Strachey (Ed.), Obra Completa de Sigmund Freud, vol.10. (Originalmente publicado en 1909)

Freud, S. (19861). Puntualizaciones psicoanalíticas sobre un caso de paranoia (Dementia paranoides) descrito autobiográficamente. In J. Strachey (Ed.), Obra Completa de Sigmund Freud, vol.12, cap.1. (Originalmente publicado en 1910)

Freud, S. (1986m). Consejos al médico en el tratamiento analítico. In J. Strachey (Ed.), Obra Completa de Sigmund Freud, vol.12, cap.6. (Originalmente publicado en 1912)

Freud, S. (1986n). Tótem y tabú. In J. Strachey (Ed.), Obra Completa de Sigmund Freud, vol.13, cap.1. 
(Originalmente publicado en 1913)

Freud, S. (1986o). Acerca de la fausse reconnaisance. In J. Strachey (Ed.), Obra Completa de Sigmund Freud, vol.13, cap. 4. (Originalmente publicado en 1914)

Freud, S. (1986p). El humor. In J. Strachey (Ed.), Obra Completa de Sigmund Freud, vol.21, cap. 4. (Originalmente publicado en 1927)

Freud, S. (1986q). La descomposición de la personalidad psíquica. In J. Strachey (Ed.), Obra Completa de Sigmund Freud, vol.22, conferencia 31. (Originalmente publicado en 1933)

Freud, S. (1986r). Moisés y la religión monoteísta. In J. Strachey (Ed.), Obra Completa de Sigmund Freud, vol.23, cap. 1, C. (Originalmente publicado en 1939)

Hooper, T. [Director] (2010). El discurso del Rey [Película]. Reino Unido. Bedlam productions.

Vives, J. M. (2001). La place de la voix dans la filiation. Cliniques Méditerranéennes, 1(63), 157-166. doi: $10.3917 / \mathrm{cm} .063 .0157$

\section{Endereço para correspondência:}

Araceli Colín Cabrera

Endereço: Cerro de las Campanas, s/n Colonia Las

Campanas Querétaro, Qro. C.P. 76010

Email: aracolinca@gmail.com 